\title{
HEALTH, WELL-BEING AND SUSTAINABLE HOUSING
}

\author{
Agne PROCHORSKAITE ${ }^{1}$ and Vida MALIENE $2 \bowtie$ \\ ${ }^{1}$ School of the Built Environment, Liverpool John Moores university, Byrom street, Liverpool \\ L3 3AF, United Kingdom \\ 2 School of the Built Environment, Liverpool John Moores university, Byrom street, Liverpool \\ L3 $3 A F$, United Kingdom \\ E-mail:V.Maliene@ljmu.ac.uk
}

Received 22 December 2011; accepted 16 April 2012

\begin{abstract}
Sustainability of the built environment is an increasingly prominent concern in academic and policy discussions in the UK and EU. Initiatives such as the Code for Sustainable Homes in the UK have been developed to aid integration of sustainability principles into housing developments. Primary focus in this field has been largely on environmental sustainability (particularly energy efficiency) with less attention paid to social and economic factors. This article argues that health and well-being issues need greater consideration within current sustainable housing policy and developments. Three key reasons are presented in support of this argument: (i) Creation of greater market demand; public demand for sustainable buildings could be enhanced through greater promotion of the health and well-being benefits of sustainable housing: (ii) Time-scales; given the longevity of buildings, health considerations should be of paramount importance to avoid any possible future adverse effects: (iii) Indirect societal benefits; enhanced health and well-being can lead to wider societal and economic benefits such as lower healthcare costs. The paper then presents some of the seminal findings from health and housing literature review, outlining how these can be used to enhance sustainable housing policy and developments. The paper concludes by presenting the next stages of research.
\end{abstract}

KEYWORDS: Health; Well-being; Sustainable housing; Sustainable development; Environment; United Kingdom

REFERENCE to this paper should be made as follows: Prochorskaite, A. and Maliene, V. (2013) Health, well-being and sustainable housing, International Journal of Strategic Property Management, 17(1), pp. 44-57.

\section{INTRODUCTION}

Given the significant impact housing has on the environment and its role as a key determinant of human health, the subject of housing features heavily in both environmental protection and public health discourses. Exploring the policy and academic literature on 'sustainable housing' and 'health and housing' quickly reveals many overlapping aims and objectives between the two. However at the same time, little meaningful conceptual or practical interaction can be identified. While the issue of sustainability in the built environment has gained interest in academic, industry as well aas policy discussions (Brown and Bhatti, 2003; Williams and Dair, 2007; DCLG, 2007; Maliene and Malys, 2009), progress for the widespread 
adoption of sustainable housing has been slow (Sunikka, 2003). This paper argues that for sustainable housing to progress faster, the concept of 'sustainable housing' must incorporate greater consideration of health and well being issues.

The paper stems from ongoing research exploring health and well-being issues of sustainable housing and consists of three parts: It begins with a brief discussion on the meaning of 'sustainable housing' and then presents three arguments for why a greater consideration of health and well-being aspects is important and how this can act as a driver for sustainable housing adoption. This is followed by a number of findings from the housing and health review that are relevant for the development of sustainable housing policy and research agenda. The paper concludes with a brief overview of the next stages of the study.

\section{WHAT IS SUSTAINABLE HOUSING?}

The most widely used definition for the concept of sustainability is that presented in the Brundland Report 'Our Common Future': Sustainable development is defined as development that meets the needs of the present generation without compromising the ability of future generations to meet their own needs (World Commission on Environment and Development, 1987). This definition implies that for any development to be 'sustainable', it must achieve a balance between social, environmental and economic factors. Applying this definition to 'sustainable housing', a truly sustainable housing development would need to make provision for these three considerations.

However, the Brundland definition is not always readily transferable into a working definition that can guide practice, and sustainable housing policy is no exception. A recent report investigating the extent to which UK development industry is incorporating sustainability into practice revealed a lack of industry-wide consensus on the meaning of sustainability, and while the idealism of the Brundland definition is unlikely to provide a basis for a consensus, lack of common defining criteria is an important hindrance to implementation of sustainability in practice (Taylor Wessing LLP, 2009). A definition for 'sustainable development' is also lacking within UK legislation, policy statements and guidance related to planning, where the concept is widely referred to but not defined (Dowden, 2009).

A major implication of this lack of definition is that the term 'sustainable housing' is used in many cases to refer to environmentally sustainable housing. The social and economic elements (if at all acknowledged) tend to be treated as peripheral. For instance the UK's Code for Sustainable Homes (the Code) consists of nine categories: (i) Energy and $\mathrm{CO}_{2}$ Emissions; (ii) Water; (iii) Materials; (iv) Surface Water Run-off; (v) Waste; (vi) Pollution; (vii) Health and Well-being; (viii) Management; and (ix) Ecology. Eight of these categories cover environmental considerations, and crucially, only one considers health and well-being. Furthermore this one category considers only four issues - 'daylighting', 'sound insulation', 'private space', and 'lifetime homes'. As discussion later in the paper illustrates, health and well-being issues go far beyond these four considerations. One area of particular concern regarding the Code is the lack of criteria covering indoor air quality (Good Homes Alliance, 2008) - an issue that is gaining increasing attention due to the potentially inadequate ventilation within energy efficient buildings (Bone et al., 2010).

There is also evidence of greater focus on the environmental side of sustainability at the implementation level. For instance, Local Agenda 21 policies of regional and local councils are more focused on environmental issues and less on social and economic ones as sustainability policies tend to become the remit of environmental departments (Bond et al., 1998). While a review of UKs registered social 
landlords sustainability policies by Carter and Fortune (2007) found that this is also reflected in practice as sustainable housing developments have primarily sought to address the ecological impacts of buildings.

The situation is not helped by the lack of consensus over the sustainable housing definition in academic discussions. In much of the sustainable housing literature, the concept is often seen in narrow terms of environmental sustainability, that is, housing with minimal negative impacts on the environment (Sunikka, 2003; Sunikka and Boon, 2003; Priemus, 2005; Pickvance, 2009; Venckus et al., 2010; Winston, 2009). On the other hand, public health literature unsurprisingly focuses more on the social element of sustainability. For instance Barton et al. (2003) argue that the Brundland definition focus is clearly on people - "sustainable development is therefore about maintaining and enhancing the quality of human life - social, economic and environmental - while living within the carrying capacity of supporting ecosystems and the resource base" (p. 5). If cities are to become attractive and healthy places to live, urban planners must focus on people and how they use the built environment, instead of simply focusing on the buildings themselves (Barton and Tsourou, 2000; Burinskienè et al., 2011).

The lack of a guiding definition in sustainable housing discourse creates an imbalance between the three elements of sustainability, and two explanations can be put forward to account for the disproportionate focus on environmental issues (as opposed to social or economic factors). First reason for the environmental focus is that origins of the sustainable development concept can be traced back to the environmental movement of the 1980s. An important consequence of this is that political and organisational infrastructures in many countries are structured in such a way that anything labelled 'sustainable' will be handed over to agencies with environmental remit.
The second reason is that environmental aspects such as pollution, energy use and waste production are generally easier to quantify and measure than are social and economic considerations, and are therefore easier to implement in practice. Both of these reasons will need to be adequately addressed if attempts were made to shift the focus toward a more even balance between the three elements.

However, despite the significant impact that housing has on the environment throughout its life-cycle (Medineckiene et al., 2010; Smith et al., 1997; Užšilaitytè and Martinaitis, 2010), the imbalance between the three elements of sustainability creates a lack of a shared vision of sustainable housing, which is a significant barrier to achieving such housing (Winston, 2009). Lack of a guiding definition creates a situation where one sustainability objective can be traded for another (Williams and Dair, 2007). Perhaps it is time that a greater focus is made on people as has been suggested by public health researchers. This would achieve many of the environmental sustainability aspirations of current sustainable housing policies - not only because what is environmentally sustainable is often also healthy - but more importantly, it may yield a much needed stimulus for growth in market demand for such housing.

\section{WHY HEALTH AND WELL-BEING ISSUES NEED GREATER INTEGRATION INTO 'SUSTAINABLE' HOUSING}

Given the strong link between housing and health, there are many direct and indirect pathways through which improvements in the environmental quality of buildings will lead to improvements in human health and well-being. For instance, there is evidence of residents in efficient homes with heat recovery ventilators reporting reduced symptoms of respiratory conditions compared to occupants of control homes (Leech et al., 2004). While on broader 
neighbourhood scale, mixed use housing developments designed to lessen residents' reliance on private transport may improve health by encouraging walking and through overall lower levels of outdoor pollution (Jackson, 2003). Housing can also impact health through more indirect pathways. Environmentally unsustainable housing will indirectly impact human health through more global level effects, for instance through greater air pollution and contribution to climate change (Luria et al., 2009).

The above are just few examples of common goals that exist between environmentally sustainable housing and healthy housing. Unfortunately, given that much of the current sustainable housing developments have been built from the environmental sustainability perspective, empirical evidence is lacking to show how these developments affect the health of residents, particularly when compared to similar traditional housing developments.

However, the potential benefits of greater integration of health issues into sustainable housing policies and developments go beyond the achievement of these common goals. The following three arguments present how greater focus on health can also stimulate demand for sustainable housing and potentially justify greater investment in such developments.

\subsection{Marketing health benefits may lead to greater demand for sustainable housing}

In the UK, lack of market demand for sustainable buildings has been recognised as a major barrier to widespread integration of environmental sustainability features in housing developments (Sunikka, 2003). For instance, cases have been identified where lack of client demand for energy-efficient buildings has led to the adoption of only minimal environmental performance stipulated by statutory requirements rather than available best practice (Williams and Dair, 2007). This is exemplified by the relatively slow implementation of the Code, particularly by the private housing sector: Between 2007 and 2011, 25,057 dwellings received certification at post construction stage (DCLG, 2011a), which represents under $4 \%$ of all new build completions (DCLG, 2011b). Only 12\% of these certified homes were built for the private sector and $88 \%$ were for the public sector, which is unsurprising given that from 2008 all new social housing in England, Wales and Northern Ireland must comply with level 3 of the Code.

While overall certifications to the Code in the UK are increasing, these are dominated by the public sector housing, and there appears to be little evidence that market forces alone can drive the development of sustainable housing (Sunikka and Boon, 2003). However if sustainable homes were shown through empirical research to be healthier than conventional builds, this is likely to have a much stronger appeal to wider sections of society than advocacy for sustainable housing based solely on environmental protection grounds. With appropriate marketing, evidence of positive health associations could act as a strong motivator and lead to greater market demand for sustainable housing.

Fostering greater public demand would also go some way in addressing the uneven distribution of benefits from environmentally friendly housing measures. While benefits such as cost savings from energy efficiency or integrated renewable energy installations are mostly enjoyed by end-users of the property, investment costs must be borne by the developer and often cannot be entirely passed on to the user (Priemus, 2005). This creates a situation requiring appropriate fiscal measures and market demand to promote such investment, otherwise environmental sustainability measures may be too unprofitable for developers and landlords to take up. However, promotion of sustainable housing for health and well-being benefits may create a greater willingness among end-users to pay for investment costs passed on by developers. 
Creation of greater public demand for sustainable housing also ties in closely with the life-time environmental sustainability of such developments, which is largely influenced by occupants' behaviour and use of the building (Svane, 2002; Gimbutaite and Venckus, 2008; Zavadskas et al., 2009). Activities carried out by a household have been identified as one of the key environmental impact determinants of a dwelling (Pickvance, 2009). Also, the effectiveness of energy efficient buildings can be negated through the 'rebound effect' whereby occupants modify their behaviour counteracting the purpose of a particular environmental feature, such as increasing use of heating or air conditioning in tightly insulated buildings (Priemus, 2005). Public acceptance and demand for sustainable housing would likely lead to greater understanding and willingness by the residents to ensure correct functioning of the sustainable building features.

\subsection{The longevity of housing means that we must ensure buildings are healthy}

As action on climate change gains momentum, together with issues such as energy security and availability of natural resources, there will be increasing pressure for the built environment to be more sustainable. However, given the longevity of buildings, it is imperative that sustainable housing policy does not neglect the other components of sustainability by focusing only on ecological issues. A report by Sustainable Buildings Task Group (2004) warned that the mistakes of 1960s building boom are not repeated, and design of communities must strive for economic growth, social justice and environmental protection.

Although the goals of environmentally sustainable and healthy homes might often be aligned, policy cannot be based solely on the assumption that environmentally sustainable housing developments will always, by default and without exception enhance residents' well-being. It must be based on appropriate evidence to ensure that (i) positive health impacts are enhanced as much as possible, and (ii) the risk of any unforeseen and unintended detrimental health effects from developments intended to enhance or protect the environment is minimised.

A growing concern regarding energy efficient homes is that the air tightness of the build together with potentially inadequate ventilation may have a negative effect on the indoor air quality and therefore residents' health (Crump et al., 2009; Bone et al., 2010). In highly insulated, air tight homes, passive ventilation is generally inadequate for a suitable rate of air exchange and a mechanical system with heat recovery is necessary to ensure healthy indoor air environment. However while such systems can enhance the air quality by filtering out certain pollutants coming in from the outside, in addition to maintaining energy efficiency of the dwelling, their effectiveness relies on correct operation and maintenance (such as filter replacement).

Currently, lack of evaluation seems to be a significant problem for assessing the success of sustainable housing measures (Winston, 2009), and even less research can be found on the direct health benefits of sustainably designed residential dwellings. To bridge this gap, some inference may be possible from studies investigating health impacts of housing improvements. However, such inference must be made with caution as in one review of intervention studies Allen (2000) observed "a reluctance to probe beyond a general assumption that health will improve as housing is improved" (p. 444). An analogous situation appears to exist with regards to sustainable homes - it is assumed that health will improve with installation of environment protective measures. This paper does not seek to negate the importance of such measures by any means, but calls for greater evaluation of the health impacts of sustainable homes. 
Furthermore, greater attention needs to be paid to ensure that by focusing too much on environmental gains developers do not overlook any potentially adverse health effects. Building and housing development features with known negative effects on health are avoided in the UK through Building Regulations and the Housing Act. However some health effects associated with housing may take years or decades to manifest and may not have yet been identified. It is therefore essential that the substantial (albeit incomplete) body of knowledge on the housing-health relationship is used in the development and implementation of sustainable housing in order to minimise the possibility of any adverse effects.

\subsection{Improvement of public health could justify higher costs of sustainable housing}

Another major barrier to a wider adoption of sustainable housing that has been identified is the perceived cost of such developments (Sunikka, 2003). While this may become minimised through greater market demand for sustainable homes (as discussed above), in the shorter-term, sustainable housing policy may be promoted by the argument that enhanced public health and well-being through sustainable housing can lead to wider societal and economic benefits, leading to monetary savings elsewhere (such as lower healthcare costs, reduced absenteeism, higher productivity). The argument that greater investment in healthy homes can lead to wider economic and societal benefits is a motif found in housing and health literature. This argument is generally found in two forms:

Firstly, healthy housing can lead to potentially measurable (at least by approximation) savings in health care. Miles and Jacobs (2008) argue that when the range of health implications related to housing are not fully considered by planners during the planning processes, the result is a cost shifting between the housing and health care sectors of the economy. In other words, the cost of unhealthy housing is reflected in the medical costs, and in England, the Buildings Research Establishment has estimated that poor housing is costing the National Health Service over $£ 600$ million a year (Ormandy et al., 2010). Such cost-benefit discussions have prompted some observers to argue that given the existence of substantial evidence linking poor health to low quality housing, investment in high quality housing may also be driven by health considerations and can lead to significant health improvements (Bonnefoy et al., 2004).

The second form of argument is more indirect and is based on the observation of the close relationship between housing quality and socio-economic status (SES). SES is closely aligned to health as research has linked low SES to poorer health and shorter life-expectancy than for individuals with high SES (Fuller-Thomson et al., 2000). In turn, the housing sector has been noted as a significant producer of social inequality (Dunn, 2002). The nature of these linkages are highly complex, and only indirect associations can be discussed, however improvement in the quality of housing through environmental (e.g. energy efficiency) measures and health considerations (e.g. improved air quality) can improve health and lower heating costs thereby contributing to improving the socio-economic position of a household.

\section{HOUSING AND HEALTH RESEARCH - STATE OF KNOWLEDGE AND LESSONS FOR SUSTAINABLE HOUSING}

Research into the health impacts of housing has a relatively long history. Associations between health and housing were noted in the early $19^{\text {th }}$ century when the link between high incidence of disease and poor quality housing 
was observed in industrialised cities of the UK (Chadwick, 1842). This gave rise to the public health movement, and the targeted action to improve sanitation, over-crowding and the basic quality of the built environment leading to a decline in the rates of infectious diseases (Perdue et al., 2003).

Perhaps as a consequence of this success, links between urban planning and health became less prominent (Barton and Tsourou, 2000; Dunn, 2002). Yet while incidence of infectious diseases attributable to housing has diminished, the built environment has re-emerged as a priority for public health as more complex, chronic health conditions linked to housing have been acknowledged (e.g. allergies, skin irritations, asthma and other respiratory illnesses) (Krieger and Higgins, 2002; Miles and Jacobs, 2008).

The substantial body of research into housing impacts on health has been collated and reviewed by numerous authors (for example Bonnefoy, 2007; Carr-Hill, 2000; Fuller-Thomson et al., 2000; Krieger and Higgins, 2002). However despite the quantity of research in this field, a common conclusion found in literature reviews is a lack of overall integration of individual studies into a holistic framework that could help define the housing-health relationship. Fuller-Thompson et al. (2000) summed up existing research as "narrowly focused, fragmented, and of marginal practical relevance to either housing or health policy" (p. 109).

In recognition of this criticism, attempts have been made to unify and integrate existing research into models and frameworks that could guide understanding of this important relationship. While this is still work in progress, the empirical and conceptual developments in housing and health research are worth the consideration in sustainable housing discourse. The remainder of this section will outline three key themes that feature prominently in housing and health research and have significant relevance to sustainable housing policy and developments.

\subsection{Housing and health definitions}

Although the terms 'health' and 'housing' may appear straightforward, both in fact are broad in meaning and can be interpreted in different ways. Defining these terms is necessary not only to minimise ambiguity, but also aid establishment of a platform for discussion of this subject.

Health. The definition of health generally depends on the context in which the term is being used. For instance health practitioners will use the more traditional definition based on the biomedical model that focuses on the physical and chemical processes. However, perhaps the most widely used definition of 'health' - as defined in the preamble to the Constitution of the World Health Organisation (WHO) - is broader and encompasses the social dimension of human condition: 'health is a state of complete physical, mental and social well-being and not merely the absence of disease or infirmity' (WHO, 1948).

The nature of how health is understood has important implications for housing and health policy as well as research. Historically, housing improvement policies were primarily based on the biomedical model as a particular housing feature was linked to a specific and often acute health condition, such as damp conditions leading to respiratory illness. This led to targeted action on that housing feature to minimise the source of the particular negative health impact. However, recent decades have seen a conceptual shift within public health policy from the biomedical, and hence largely reactive model, to a broader one that incorporates health promotion as well as social, lifestyle and psychological aspects (Barton and Tsourou, 2000; Stewart, 2005). Housing is now increasingly being understood as a determinant of health not only from the physical symptoms, but through numerous direct and indirect pathways, including mental health and social well-being. 
This shift towards a broader conceptual meaning of health has several important implications for research in this field. Firstly, while a broad definition of health is perhaps more suitable for studying housing impacts, it also creates significant methodological barriers as it gives no provision of how health should be measured (Carr-Hill, 2000). Second point to note is that broader definition as presented by the WHO describes essentially a positive state (as opposed to neutral or negative). However, most of the research into the health impacts of housing to date is focused on the negative associations (Fuller-Thomson et al., 2000). As the existing knowledge of the housing-health relationship is based on such research, it begs the question of whether enough knowledge exists to build housing to promote health rather than simply avoid illness.

Housing. As with the definition of health, the term 'housing' is seen by many researchers going beyond the simple physical structure of a dwelling. In its broadest sense, housing can be divided up into three levels:

(i) The home. The intangible role of housing as a home has been linked to psychological health through the provision of a secure and protective environment (Kearns et al., 2000) and as a psychosocial symbol of achieved status (Howden-Chapman, 2004). As Fullilove and Fullilove (2000) explain, this role is distinctive from the physical 'dwelling' as the psychological idea of a 'home' is the same among groups that may have very different dwellings, such as nomadic groups.

(ii) Dwelling. Referring to the physical structure, it is primarily at this level of the 'housing' definition that most research on housing and health has been carried out. Key issues of healthy housing that have received particular attention revolve around quality and health impacts of the indoor environment; acoustics, illumination, thermal conditions, dampness, indoor air quality, building materials, and safety. However this overall body of literature has been critiqued by a number of reviewers for its fragmented nature and methodological weaknesses found in many of the studies (Fuller-Thomson et al., 2000; Shaw, 2004; Bonnefoy, 2007; Thomson et al., 2009).

(iii) The neighbourhood/community. Housing plays an important role in relation to other housing units through the creation of a community or neighbourhood. This level comprises of the social elements that impact on health, which include socioeconomic conditions, ethnic composition of the area, and the level and nature of the social interactions that are facilitated through the composition of the public area (Bonnefoy, 2004; Braubach, 2007).

The broader meanings of health and housing do add to the methodological complexities of this research field, which is perhaps why many studies focus on the biomedical definition of health and avoid making the distinctions in housing (Fuller-Thompson et al., 2000). However rather than a hindrance, these broader definitions can be viewed as an asset for conceptualising as well as implementing sustainability within housing. By encompassing psychosocial elements and human needs beyond the biomedical boundaries, 'health and well being' can be used as the central focal point for the 'social' element of sustainability. The discussions on the meaning of health found in the public health literature can contribute not only to the development of a framework, but also offer ways of measuring and implementing the social element of sustainable housing.

\subsection{Housing is a key determinant of health}

Health is determined by a complex interaction of numerous physical, chemical, behavioural and biological factors (Barton and Tsourou, 
2000). A model (Figure 1) developed by Dahlgren and Whitehead (1991) has been widely used to illustrate this interaction. Represented by the core of the model, health is primarily pre-determined by factors such as gender, age and hereditary conditions. This core is surrounded by four layers of factors whose influences generally become less direct, but nevertheless remain important. Individual lifestyle behaviour such as diet, smoking, alcohol consumption and level of exercise have a direct and significant effect on health. Community factors such as social networks influence lifestyle and therefore health of an individual. Wider societal, economic and global factors will influence health in a less direct way. These less direct factors can however have a strong influence on psychological wellbeing, which may be caused by for example stress and anxiety over employment, economy, political or global issues. Depending on how an individual is pre-conditioned to deal with these stresses (lifestyle and community levels play a major role in this), these less direct factors can

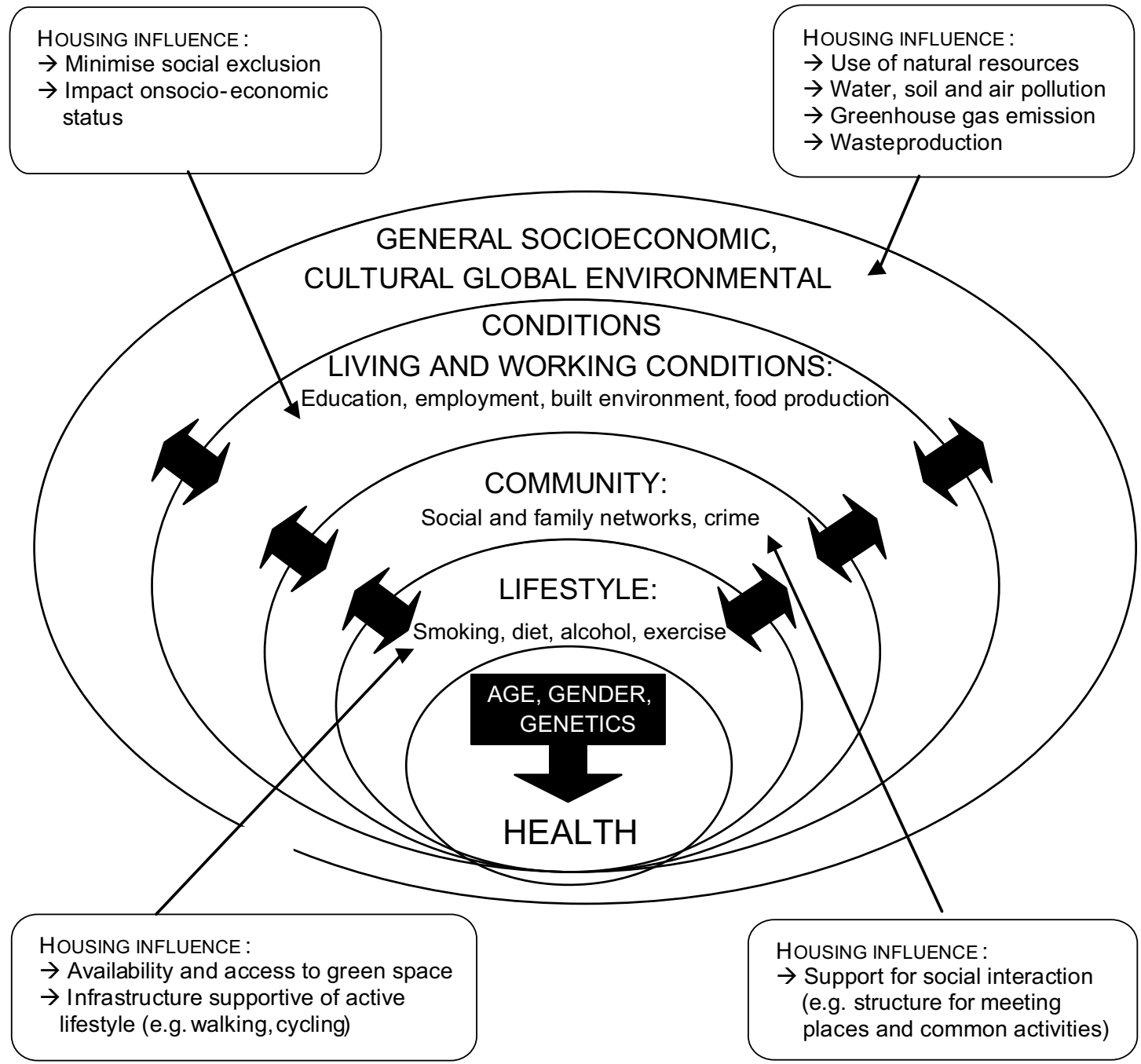

Figure 1. The determinants of health (adapted from Dahlgren and Whitehead, (1991) 
manifest into physical and/or psychological ill health.

However, it is important to note that the outlined determinants can also be enhanced or reduced by each other. Although the model places housing in the third stratum of influence, review of research into the housing and health relationship reveals the important influence that the built environment will have on other determinants, which in turn can correspond to a greater or lesser effect on health and well-being.

Design of housing developments can influence individual's behaviour by for instance encouraging walking or cycling rather than car use (Jackson, 2003). Spacious and appropriately designed kitchen facilities may encourage people to prepare home cooked meals, thereby leading to a more nutritious diet (CABE, 2009). Supportive social networks may be encouraged by design of homes and communities with meeting spaces. The socio-economic impacts of housing are complicated but well documented (Fuller-Thompson et al., 2000), while examples of housing effects on the environment range from local impacts of pollution and water to global contribution to resource depletion and greenhouse gas emission.

If housing can positively or negatively affect health by influencing the other determinants in the model, another question arises can the positive influence of housing counteract negative influences of these other factors? For example, it has been well documented that chronic stress can lead to a number of physical and mental ill-health conditions through several pathways (Easterlow et al., 2000). This is particularly problematic when stress is caused by conditions outside an individual's control such as economic uncertainties, politics and global issues. If housing was designed to provide a stronger sense of refuge and safety, and a place where one is able to choose privacy or quality time with family and friends, perhaps housing could counteract the negative influence of stress created by the other health determinants.

Such 'healing' features of buildings are not a new idea and have been investigated in the early $20^{\text {th }}$ century (Hobday, 2010). There is a substantial body of literature on hospital design and how certain features can be incorporated to speed healing and patient recovery (for example Ulrich, 2006). However, very little of this knowledge seems to be incorporated into sustainable housing in a systematic way.

\subsection{Complexity must be acknowledged and addressed through a multidisciplinary and longitudinal approach}

The disjointed nature of the housing and health literature is partly caused by the narrow, biomedical-model based interpretation of the relationship between housing and health (Lawrence, 2005). Historically, many of the housing and health linkages were explained by simple causation models, such as unsanitary housing, overcrowding, inadequate ventilation and food storage leading to illness primarily caused by infection. Today, it is increasingly acknowledged that health conditions related to housing tend to have multiple causal factors acting at different levels of housing (see section 4.1). Also, chronic health conditions and some of the less direct affects can take many years to manifest - time-scales on which very few research methodologies currently operate on.

As the complexity of current health challenges linked to housing have been acknowledged, is has become widely recognised that solutions will need to be holistic (Miles and Jacobs, 2008) requiring a cross-sectional and multidisciplinary research approach (Jackson, 2003; Srinivasan et al., 2003). Impacts of individual factors need to be evaluated against the holistic concept of housing as these will tend to be affected by numerous confounding housing variables (Bonnefoy, 2007). 


\section{NEXT STAGE OF RESEARCH}

The first stage of research was to review the literature on how sustainable housing impacts residents' health and well-being. However, given the lack of published research on health impacts of sustainable housing, a framework (Figure 2) was developed to guide the literature review to related and overlapping themes where significant levels of research do exist. Starting with the three components of 'housing', 'environmental sustainability', and 'health', substantial investigative work has been identified in the areas where each of the two components overlap. The purpose of this is to inform the central theme where all three components overlap, i.e. health and (environmentally) sustainable housing.

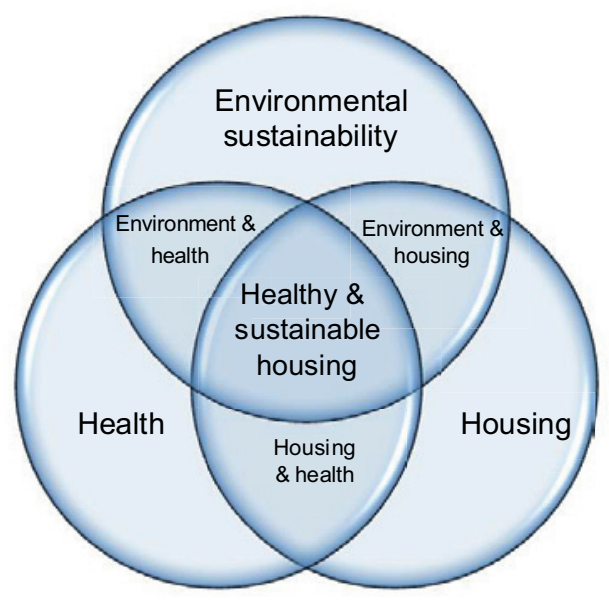

Figure 2. Guiding framework for review of health and sustainable housing literature

'Housing and health' theme forms the largest of the three areas, reflecting the long history of research into how housing impacts health. A smaller number of publications have been identified for 'sustainable housing' and 'health and sustainable development' themes. Again, these generally tend to focus on the environmental aspects of sustainable development. Nevertheless, all three areas have significant contributions to make in conceptualis- ing how sustainable housing can impact health as well as providing guidance for developing ways of measuring this impact.

The current aim of the ongoing research is to explore the different priorities that residents, developers and social landlords have towards the socioeconomic and environmental components of sustainable housing. The review of health impacts of housing as well as existing standards for sustainable and/or energy efficient housing will be used to establish a set of criteria covering health, well-being, socioeconomic and environmental issues. Formed into a survey, this will enable analysis of the different levels of importance that key stakeholders attribute to these elements of sustainable housing - the assumption being that the residents will attach greater importance to health and well-being attributes over environmental features of a particular dwelling. The ultimate aim of the research is to use this evidence and develop a decision-making tool that will enable stakeholders to evaluate the sustainability of any housing development with an emphasis on health and well-being of the residents.

\section{CONCLUSIONS}

Despite the growing impetus for sustainable housing, progress to date has been relatively slow given the low market demand and lack of a guiding definition for sustainable housing. Compared to environmental protection measures, health and well-being issues have received significantly less attention in sustainable housing research, policy discourse, and developments. Yet opportunity exists to boost demand and implementation by focusing on the positive impacts on health of sustainable housing. Review of the extensive body of research into housing impacts on health support the importance of greater health focus in sustainable housing policy. Healthy homes and environmentally sustainable housing share many common goals and this is a good oppor- 
tunity for the two areas to 'unite forces' for a greater chance of success in achieving these objectives.

The aim of the ongoing research is to explore the different levels of importance that key housing stakeholders assign to the constituent attributes of sustainable homes. Looking in particular at the health, well being and environmental sustainability features, the investigation will test the assumption that residents attach greater importance to healthier homes - thereby providing evidence to the argument presented here that health and wellbeing benefits should be used to encourage sustainable housing development, as opposed to promotion based on environmental protection grounds.

\section{REFERENCES}

Allen, T. (2000) Housing renewal - doesn't it make you sick?, Housing Studies, 15(3), pp. 443-461. http://dx.doi.org/10.1080/02673030050009276

Barton, H., Grant, M. and Guise, R. (2003) Shaping neighbourhoods. A guide for health, sustainability and vitality. London: Spon Press.

Barton, H. and Tsourou, C. (2000) Healthy urban planning: A WHO guide to planning for people. London: Spon Press.

Bond, A. J., Mortimer, K. J. and Cherry, J. (1998) The focus of Local Agenda 21 in the United Kingdom, Journal of Environmental Planning and Management, 41(6), pp. 767-776. http:// dx.doi.org/10.1080/09640569811416

Bone, A., Murray, V., Myers, I., Dengel, A. and Crump, D. (2010) Will drivers for home energyefficiency harm occupant health?, Perspectives in Public Health, 10(5), pp. 233-238. http:// dx.doi.org/10.1177/1757913910369092

Bonnefoy, X. (2004) The policy relevance of housing and health - an international perspective. In: Proc. of the $2^{\text {nd }}$ WHO international housing and health symposium, September 29 - October 1, 2004, Vilnius, Lithuania.

Bonnefoy, X., Annesi-Maesano, I., Aznar, L., Braubach, M., Croxford, B., Davidson, M., et al. (2004) Review of evidence on housing and health. Fourth Ministerial Conference on Envi- ronment and Health. Budapest, Hungary, June 23-25, 2004, Budapest, Hungary.

Bonnefoy, X. (2007) Inadequate housing and health: an overview, International Journal of Environment and Pollution, 30(3/4), pp 411-429.

http://dx.doi.org/10.1504/IJEP.2007.014819

Braubach, M. (2007) Residential conditions and their impact on residential environment satisfaction and health: Results of the WHO large analysis and review of European housing and health status (LARES) study, International Journal of Environment and Pollution, 30(3/4), pp. 384-403. http://dx.doi.org/10.1504/ IJEP.2007.014817

Brown, T. and Bhatti, M. (2003) Whatever happened to 'housing and the environment'?, Housing Studies, 18(4), pp. 505-515. http:// dx.doi.org/10.1080/02673030304253

Burinskienè, M., Rudzkienè, V. and Venckauskaitè, J. (2011) Effects of quality of life on the price of real estate in Vilnius city, International Journal of Strategic Property Management, 15(3), pp. 295-311. http://dx.doi.org/10.3846/164871 5X.2011.617857

CABE (2009) Space in new homes: What residents think. [Online] Commission for Architecture and the Built Environment. Available at http://www. cabe.org.uk/publications/space-in-new-homes

Chadwick, E. (1842) Report on the sanitary condition of the labouring population of Great Britain. London HMSO.

Carr-Hill, R. (2000) Impact of housing conditions upon health status, Hume Papers on Public Policy, 8(4), pp. 12-35.

Carter, K. and Fortune, C. (2007) Sustainable development policy perceptions and practice in the UK social housing sector, Construction Management and Economics, 25(4), pp. 399-408. http://dx.doi.org/10.1080/01446190600922578

Crump, D., Dengel, A. and Swainson, M. (2009) Indoor air quality in highly energy efficient homes - a review. NHBC Foundation Report NF18 July 2009.

Dahlgren, G. and Whitehead, M. (1991) Policies and strategies to promote social equity in health. Institute of Futures Studies. Stockholm.

DCLG (2007) Homes for the future: more affordable, more sustainable. Department for Communities and Local Government (DCLG), The Stationery Office, London. 
DCLG (2011a) Code for sustainable homes and energy performance of buildings: Cumulative and quarterly data for England, Wales and Northern Ireland up to March 2011, Statistical Release. May 2011. Department for Communities and Local Government (DCLG).

DCLG (2011b) Housing stock, England - dwelling stock estimates, England, 2011. Statistical Release, 30 November 2011. Department for Communities and Local Government (DCLG).

Dowden, M. (2009) Does the UK have a sustainable housing policy? In: ENHR conference on changing housing markets: integration and segmentation proceedings, University of Economics, Prague, Czech Republic, 28 June - 1 July, 2009.

Dunn, J. R. (2002) Housing and inequalities in health: A study of socioeconomic dimentions of housing and self reported health from a survey of vancouver residents, Journal of Epidemiology and Community Health, 56(9), pp. 671-681. http://dx.doi.org/10.1136/jech.56.9.671

Easterlow, D., Smith, S. J. and Mallinson, S. (2000) Housing for health: The role of owner occupation, Housing Studies, 15(3), pp. 367-386. http://dx.doi.org/10.1080/02673030050009230

Fuller-Thomson, E., Hulchanski, J. D. and Hwang, S. (2000) The housing/health relationship: What do we know?, Reviews on Environmental Health, 15(1-2), pp. 109-133. http://dx.doi. org/10.1515/REVEH.2000.15.1-2.109

Fullilove, M. T. and Fullilove, R. E. (2000) What's housing got to do with it? American Journal of Public Health, 90(2), pp. 183-184. http://dx.doi. org/10.2105/AJPH.90.2.183

Gimbutaite, I. and Venckus, Z. (2008) Air pollution burning different kinds of wood in small power boilers, Journal of Environmental Engineering and Landscape Management, 16(2), pp. 97-103. http://dx.doi.org/10.3846/16486897.2008.16.97-103

Good Homes Alliance (2008) Code for Sustainable Homes (CSH): Technical comments regarding Levels 3 and 4 - energy. GHA position paper, March 2008.

Hobday, R. (2010) Designing houses for health - A review. Commissioned by the VELUX Company Ltd.

Howden-Chapman, P. (2004) Housing standards: A glossary of housing and health, Journal of Epidemiology and Community Health,
58(3), pp. 162-168. http://dx.doi.org/10.1136/ jech.2003.011569

Jackson, R. J. (2003) The impact of the built environment on health: An emerging field, American Journal of Public Health, 93(9), pp. 13821383. http://dx.doi.org/10.2105/AJPH.93.9.1382

Kearns, A., Hiscock, R., Ellaway, A. and MaCintyre, S. (2000) 'Beyond four walls'. The psycho-social benefits of home: Evidence from West Central Scotland, Housing Studies, 15(3), pp. 387-410. http://dx.doi.org/10.1080/02673030050009249

Krieger, J. and Higgins, D. L. (2002) Housing and health: Time again for public health action, American Journal of Public Health, 92(5), pp. 758-768. http://dx.doi.org/10.2105/ AJPH.92.5.758

Lawrence, R. J. (2005) Housing and health: A way forward, Built Environment, 31(4), pp. 315-325. http://dx.doi.org/10.2148/benv.2005.31.4.315

Leech, J. A., Raizenne, M. and Gusdorf, J. (2004) Health in occupants of energy efficient new homes, Indoor Air, 14(3), pp. 169-173. http:// dx.doi.org/10.1111/j.1600-0668.2004.00212.x

Luria, P., Lyons, M., el Azzeh, S. and Sarsharet, M. (2009) Fact Sheet 2: Public health aspects of sustainable buildings. Liverpool John Moores University Centre for Public Health.

Maliene, V. and Malys, N. (2009) High-quality housing - A key issue in delivering sustainable communities, Building and Environment, 44(2), pp. 426-430. http://dx.doi.org/10.1016/j. buildenv.2008.04.004

Medineckiene, M., Turskis, Z. and Zavadskas, E. K. (2010) Sustainable construction taking into account the building impact on the environment, Journal of Environmental Engineering and Landscape Management, 18(2), pp. 118-127. http://dx.doi.org/10.3846/jeelm.2010.14

Miles, R. and Jacobs, D. E. (2008) Future directions in housing and public health: Findings from Europe with broader implications for planners, Journal of the American Planning Association, 74(1), pp. 77-89. http://dx.doi. org/10.1080/01944360701784287

Ormandy, D., Bryson, J., Battersby, S., Nicol, S., Flynn, R., White, K. and Mason, V. (2010) Linking housing conditions and health. A report of a pilot study into the health benefits of housing intervention. Warwick Law School with Building Research Establishment. 
Perdue, W. D., Stone, L. A. and Gostin, L. O. (2003) The built environment and its relationship to the public's health: The legal framework, American Journal of Public Health, 93(9), pp. 13901394. http://dx.doi.org/10.2105/AJPH.93.9.1390

Pickvance, C. (2009) The construction of UK sustainable housing policy and the role of pressure groups, Local Environment, 14(4), pp. 329-345. http://dx.doi.org/10.1080/13549830902764712

Priemus, H. (2005) How to make housing sustainable? The Dutch experience, Environment and Planning B: Planning and Design, 32(1), pp. 5-19. http://dx.doi.org/10.1068/b3050

Shaw, M. (2004) Housing and public health, Annual Review of Public Health, 25, pp. 397418. http://dx.doi.org/10.1146/annurev.publhealth.25.101802.123036

Smith, M., Whitelegg, J. and Williams, N. (1997) Life-cycle analysis of housing, Housing Studies, 12(2), pp. 215-229. http://dx.doi. org/10.1080/02673039708720892

Srinivasan, S., O'Fallon, L. R. and Dearry, A. (2003) Creating healthy communities, healthy homes, healthy people: Initiating a research agenda on the built environment and public health, American Journal of Public Health, 93(9), pp. 14461450. http://dx.doi.org/10.2105/AJPH.93.9.1446

Stewart, J. (2005) A review of UK housing policy: Idelogy and public health, Public Health, 119(6), pp. 525-534. http://dx.doi.org/10.1016/j. puhe.2004.07.006

Sunikka, M. (2003) Fiscal instruments in sustainable housing policies in the EU and the accession countries, European Environment, 13(4), pp. 227-239. http://dx.doi.org/10.1002/eet.318

Sunikka, M. and Boon, C. (2003) Environmental policies and efforts in social housing: The Netherlands, Building Research \& Information, 31(1), pp. 1-12. http://dx.doi. org/10.1080/0961321021000013858

Sustainable Buildings Task Force (2004) Better buildings - better lives. Sustainable Buildings Task Force.

Svane, Ö. (2002) Nordic consumers and the challenge for sustainable housing, Sustainable Development, 10(1), pp. 51-62. http://dx.doi. org/10.1002/sd.178

Taylor Wessing LLP (2009) Behind the green façade - Is the UK development industry really embracing sustainability? Taylor Wessing Sustainability Report.
Thomson, H., Thomas. S., Sellstrom, E. and Petticrew, M. (2009) The health impacts of housing improvement: A systematic review of intervention studies from 1887-2007, American Journal of Public Health, 99(S3), pp. S681-S692. http:// dx.doi.org/10.2105/AJPH.2008.143909

Ulrich, R. S. (2006) Essay: Evidence-based healthcare architecture, The Lancet, 368, pp. S38-S39. http://dx.doi.org/10.1016/S01406736(06)69921-2

Užšilaityte, L. and Martinaitis, V. (2010) Search for optimal solution of public building renovation in terms of life cycle, Journal of Environmental Engineering and Landscape Management, 18(2), pp. 102-110. http://dx.doi.org/10.3846/ jeelm. 2010.12

Venckus, N., Bliūdžius, R., Endriukaitytè, A. and Parasonis, J. (2010) Research of low energy house design and construction opportunities in Lithuania, Technological and Economic Development of Economy, 16(3), pp. 541-554. http:// dx.doi.org/10.3846/tede.2010.33

WHO (1948) Preamble to the Constitution of the World Health Organization as adopted by the International Health Conference, New York, 19-22 June, 1946. Official Records of the World Health Organization (WHO), no. 2, p. 100.

Williams, K. and Dair, C. (2007) What is stopping sustainable building in England? Barriers experienced by stakeholders in delivering sustainable development, Sustainable Development, 15(3), pp. 135-147. http://dx.doi. org/10.1002/sd.308

Winston, N. (2009) Regeneration for sustainable communities? Barriers to implementing sustainable housing in urban areas, Sustainable Development, 18(6), pp. 319-330. http://dx.doi. org/10.1002/sd.399

World Commission on Environment and Development (1987) Our common future. Oxford: Oxford University Press.

Zavadskas, E. K., Kaklauskas, A., Turskis, Z. and Kalibatas, D. (2009) An approach to multiattribute assessment of indoor environment before and after refurbishment of dwellings, Journal of Environmental Engineering and Landscape Management, 17(1), pp. 5-11. http:// dx.doi.org/10.3846/1648-6897.2009.17.5-11 